\title{
Andanzas de una oreja rebanada en algunos villancicos novohispanos
}

\author{
Porque en la Iglesia se estila \\ que se canten cosas nuevas, \\ y si en su jacarandina \\ no hay algo de novedad, \\ en vano se desgañita, \\ porque nadie ha de escucharle. \\ Sor JuANA INÉS DE LA CRUZ, \\ Villancicos a la Asunción, 1690
}

El carácter inflexible del dogma católico en relación con las Sagradas Escrituras debió causar muchos dolores de cabeza a todos los villanciqueros en el orbe hispánico. Por un lado, los villancicos debían celebrar cada año los mismos e inamovibles episodios concernientes a las fiestas religiosas más importantes: la Navidad, la Encarnación, la Concepción, la Asunción. Y por otro, gran problema, debían mantener la atención de un público ávido de novedades y, por si fuera poco, dejar contenta también a la jerarquía eclesiástica, quien costeaba los gastos de la celebración.

Los juegos de villancicos dedicados a san Pedro eran particularmente abundantes en la Nueva España. Salvo no más de dos excepciones, los motivos en estos villancicos provienen de la Biblia. Algunos, por ofrecer mayores posibilidades líricas, por ser más populares, por ser capitales en la vida del santo o por todo ello a la vez, nunca faltan: las negaciones, el canto del gallo y las lágrimas; el santo como pescador y capitán de la nave de la Iglesia (pontífice romano); o el hecho de que pidió ser crucificado de cabeza. Otros, con menos fre- 
cuencia, también aparecen: el caminar del santo sobre las aguas, la resurrección de Tabita, su oposición a que Cristo lave sus pies antes de la última cena, su encarcelamiento, el episodio de Simón Mago, la curación del cojo, etc. En total, estos motivos no deben rebasar la veintena: no parecen suficientes para los muchos años de intensa producción de villancicos a san Pedro durante la Colonia. ¿Cómo hacer, entonces, que cada juego sea único y deje contentos a los concurrentes?

En una selección de villancicos novohispanos a san Pedro de la segunda mitad del XVII (1654-1692) puede verse un ejemplo de cómo nuestros autores logran que su juego de villancicos sea novedoso a pesar del carácter fijo y repetitivo de la materia prima con la que trabajan. Todos sabían que san Pedro no iba a hacer nada nuevo el año entrante pero, ¿qué tal si el villanciquero sí? En este caso, la novedad estriba en la forma como es tratado, en diversos villancicos, el motivo de la oreja de Malco, cortada por Pedro en el huerto.

El pasaje de Malco narra que, cuando los soldados llegan al huerto para arrestar a Jesús, Pedro, "que tenía una espada, la desenvainó e hirió con ella a un siervo del sumo sacerdote, cortándole la oreja derecha (Este siervo se llamaba Malco)" (Juan 18: 10). Un versículo, ni más ni menos. ${ }^{1}$

Uno de los recursos empleados por los autores de villancicos para hablar del violento episodio en el huerto es el poema "en metáfora de" (por decirlo con Martha Lilia Tenorio) alguna disciplina, o (con Méndez Plancarte) alegorizante. Sor Juana Inés de la Cruz, en sus villancicos a san Pedro de 1677, presenta al santo "en metáfora de" maestro de esgrima. He de decir que es la que más sabe sacar jugo del motivo pues es la única, entre los autores que he revisado, que le dedica una composición entera (una jácara). He aquí una cuarteta:

Allá va, cuerpo de Cristo, de Esgrima el mejor maestro,

\footnotetext{
${ }^{1}$ Juan es el único que atribuye a Pedro este ataque: los villanciqueros, necesitados como estaban de material, le tomaron la palabra a este evangelista y no a los otros.
} 
que amilanó a los Carranzas, que arrinconó a los Pachecos.

$(248, \text { vv. } 10-13)^{2}$

Desconozco si la ocurrencia de presentar a Pedro como maestro de esgrima es original de sor Juana, pero no es improbable que efectivamente lo sea. En sus notas a este villancico, Méndez Plancarte alude a la gran popularidad de Jerónimo de Carranza y Luis Pacheco de Narváez como maestros de esgrima, pero no da ejemplos de otros poetas que los hayan equiparado con el santo. Martha Lilia Tenorio, ni en su texto Los villancicos de Sor Juana ni en su artículo "Sor Juana y León Marchante", apunta que la jerónima haya tomado esta idea de algún otro villanciquero o poeta español.

Sea como sea, la metáfora tuvo éxito pues Pedro de Soto Espinosa, en sus villancicos poblanos a san Pedro de 1688, vuelve a emplearla en una jácara. Si la idea es de sor Juana, tendríamos que pensar que este poeta recibió influencia directa de la monja:

El que si arranca la Joja. ${ }^{3}$

el que si juega la blanca, ${ }^{4}$

se le rinden los Pachecos

y le tiemblan los Carranzas.

El que esgrimiendo el acero, contra aquella vil canalla, con un revés muy derecho

a Malco una oreja arranca.

(Soto Espinosa, s.f.)

${ }^{2}$ Sor Juana Inés de la Cruz, Obras completas, t. II: Villancicos y letras sacras. Cito los villancicos de sor Juana, y los atribuidos a ella, siempre por esta edición; de aquí en adelante, indico entre paréntesis el número de la composición y, a continuación, el número de los versos.

${ }^{3}$ Arrancar la espada: "es desnudarla o desenvainarla para reñir con otro" (Dicc. $A u t$.). Aunque es obvio que aquí significa 'espada', no he encontrado en ningún otro lado la palabra joja.

${ }^{4}$ Blanca: "por antonomasia se entiende la espada" (Dicc. Aut.). 
La metáfora de Pedro como maestro en el arte de la esgrima no es la única para hablar de la oreja de Malco. En el juego de villancicos al que ya aludimos, sor Juana trata el mismo motivo en otras dos composiciones del tipo "en metáfora de". En la primera, Pedro es un profesor de latinidad que nos enseña cómo escribir con sangre la cesura cuando corta la oreja a Malco, quien con un furor sin mensura había ido a arrestar al Maestro:

Viendo a Malco sin mensura, del furor a que le incita su locura, le puso con sangre escrita la cesura. (246, vv. 25-29)

En la segunda, la monja presenta el episodio de la oreja de Malco "en metáfora de" disputa escolástica:

Mejor las razones hila vuestro acero sin misterio, pues cuando su corte afila contra Malco, arguye en "ferio", y en "caellarem" con la ancilla.

(247, vv. 50-54)

Además de los villancicos "en metáfora de" o alegorizantes, cuando hablan de la oreja de Malco, los villanciqueros suelen también emplear el recurso de presentar a Pedro como un bandolero o como un valentón. No sé si la idea venga de allí, pero dice Cristo cuando han ido a arrestarlo al huerto: "Han salido a arrestarme con espadas y palos, como si fuera un bandido" (Marcos, 14: 48). En unos villancicos anónimos que se cantaron en Puebla en 1680, Pedro aparece como un "campeón del hampa", cuya mayor hazaña fue poner "su red y trono" en la "Curia Romana". Antes de eso hacía cosas menos impresionantes, como luchar con la espada contra Malco y otros soldados: 
En el huerto con Malco y las tropas

montanteaba.

¡Proeza rara!

¡Óiganlas!

¡Cántenlas!

$(\text { xviii, vv. 7-8 })^{5}$

En el mismo juego, Pedro aparece en una jácara (muy sanguinolenta para ser de sor Juana) como un "Campeón valiente" y "veterano Guerrero", que decidió servir "orejones" (rebanadas de fruta seca) como postre en la última cena:

Cercenóle la melena; y cimbrándole el celebro, a Malco le hacía el plato de orejones, cuando menos.

(xxii, vv. 25-28)

La ingeniosa idea del plato de orejones reaparece en un juego de villancicos de 1692 (también atribuido a sor Juana por Méndez Plancarte). Esta vez en la ensalada final del juego, en donde se habla de unos "crudos valentones":

Pues allá va buen platillo

del Príncipe, que raciones

en el Huerto repartía

a muchos juntos de un golpe.

Malco pensó que le hacían

el platillo de Gigote, ${ }^{6}$

\footnotetext{
${ }^{5}$ Méndez Plancarte atribuye este villancico a la Décima Musa, pero me parece que no hay nada (más que la pura intuición del estudioso) que permita probar tal atribución.

${ }^{6}$ Gigote: "Especie de guisado que se hace rehogando la carne en manteca y picándola en piezas muy menudas; se pone a cocer en una cazuela con agua y después se sazona con diversas especias" (Dicc. Aut.).
} 
y al fin tocó de machete

sus tajadas de Orejones.

(lxxxii, vv. 13-20)

Otra forma de hablar de la oreja de Malco es poner la hazaña en boca de los pintorescos personajes que aparecen, casi siempre, en el último nocturno de los juegos (los negros, los portugueses, y ya en el siglo XVIII, los italianos). El atractivo radica en que cada uno de estos habla del episodio con su pseudolecto característico. Sor Juana, al tocar este motivo en su juego de 1677, hace hablar a un "mestizo" de "voces arrogantes", quien se refiere a Pedro como un valentón y lo compara, aprovechando el equívoco, con un bravo "orejano" u "orejudo" (entendido como "indio" y a la vez como "cortador de orejas"):

Hoy es el Señor San Pedro que fue la piedra de Cristo, y allá en el Huerto, orejano se hizo de piedra y cuchillo.

(249, vv. 13-16)

Este juego con los "orejudos" u "orejanos" se usó desde muy temprano en la Nueva España para hablar del pasaje de Malco y es, en definitiva, un rasgo que da un color local al género. Es probable que sor Juana lo haya tomado de las Chanzonetas a san Pedro de 1654 (consideradas por Méndez Plancarte como el primer juego completo de villancicos en tierras novohispanas) $;^{7}$ en ellas, la voz lírica introduce a los "orejanos" y les atribuye, como sor Juana, la piedra y el cuchillo como armas características:

Los orejanos, por Malco, piedra y cuchillo aperciben,

${ }^{7}$ Hoy sabemos que no es así: “Al parecer, los juegos novohispanos más tempranos se remontan a 1648 [a san Laurencio en Puebla], aunque pudiera ser que la práctica (particularmente en la ciudad de México) se remontara a 1638 y haya sido anual" (Tenorio, Los villancicos de Sor Juana, 45). 
porque sus orejas Pedro

o no rebane o no birle.

(Méndez Plancarte, Poetas novohispanos, 107)

Asimismo, en el juego de 1688 escrito por Soto Espinosa habla de Malco un "mestindio / que es hijo de algo", quien asegura que, de haber estado él en el huerto, no solo hubiera ayudado al santo a cortarle una oreja al siervo del sumo sacerdote, sino le hubiera cortado la otra:
Allí mi lo escochar yo, cuanto los sampenitados cerraron a su Maestro le cortó una oreja a Marco.
Como mijuelca por tíos si yo allí intonces me jallo, si tú una oreja li cortas, yo se las cortar entrampos.

(Soto Espinosa, s.f.)

Exactamente el mismo día que se cantaron los villancicos de Soto Espinosa, solo que en México, Gabriel de Santillana hace hablar disparates a un sacristán, quien sorprende a un incauto con su terrible latín. Al hablar de Malco dicen:

1. Sólo a la sombra de Pedro los enfermos sanan hoy.

2. Dígalo Malco en el huerto si a su vista se asombró.

1. En latín lo has de decir, pues esa es la intención.

2. Sanctes erant pedes nostros

Lauda Deum tuum Sion.

¿Qué te parece, Benito?

1. Bendito el que te crió.

(Tenorio, Poesía Novohispana, 767) 
Vale la pena, por último, indicar otros dos recursos empleados por los villanciqueros novohispanos para hablar de la oreja de Malco. El primero es de Diego de Ribera en su juego de villancicos cantado en México en 1673. Él decide hablar de la oreja de Malco en elegantes esdrújulos, idea que toma de Agustín de Salazar y Torres. Constituye este villancico uno de los varios antecedentes del célebre romance de sor Juana "Lámina sirva el cielo al retrato...":

Del magnífico Pedro me asombra colérico impulso cortando una oreja, pálido en oyendo preguntas, tímido en llegando a respuestas.

(Tenorio, Poesía Novohispana, 767)

El otro recurso digno de ser mencionado, por lo original, está en un juego de 1684 atribuido por Méndez Plancarte a sor Juana. Uno de los villancicos del primer nocturno remata cada una de sus coplas con el título o alguna frase (que debía ser muy popular entonces) de una comedia. La copla que habla del motivo de Malco remata con una frase, y no con el título, de una pieza teatral, como pensó Méndez Plancarte. Proviene de la escena III del acto segundo de $L a$ toquera vizcaína de Juan Pérez de Montalván:

Por ahora, airoso queda el buen Viejo; que alentado, de la una oreja le veda a un judigüelo, y lo obrado bueno va, si no se enreda. $(\text { xliii, 19-23) })^{8}$

\footnotetext{
${ }^{8}$ Sorprende (sobre todo si este villancico fuera de sor Juana) la cantidad de comedias mencionadas en mitad del oficio religioso cuando pensamos en la postura de Antonio Núñez de Miranda para con el teatro profano, que debieron compartir otros más: "Ni por el pensamiento os pase leer comedias, que son la peste de la juventud y landre de la honestidad" (apud Alatorre, 615). Ahora bien, el recurso, aunque no es tan frecuente, aparece también en unas redondillas a san Diego "En títulos de comedias" (Marchante, Obras poéticas póstumas, t. II, 340). Hay otra composición con un recurso parecido dedicada a santa Clara: unas coplas "En metáfora de comedia" (366).
} 
Los ejemplos anteriores dejan bien claro que los villanciqueros no se limitan solo a poner en verso el pasaje bíblico al que refieren. De un par de líneas han hecho, como vimos, versos que se extienden por un periodo de alrededor de cincuenta años. Para lograrlo, han tenido que hacer insospechados malabares poéticos y han echado mano de todos los recursos que tenían a su alcance: los villancicos "en metáfora de", los de bandoleros y valentones, los de sacristanes y "mestindios", los versos esdrújulos y hasta los títulos y diálogos de comedias famosas. En este caso, todos los recursos empleados, excepto en una ocasión, han tenido el objetivo de hacer reír o, al menos, provocar una sonrisita: al parecer el episodio de la oreja de Malco les resultaba a nuestros escritores un tanto cómico, no se prestaba para un tratamiento serio.

No en balde es sor Juana la autora a quien más hemos citado aquí: sus vastos conocimientos en un sinfín de materias le permitían jugar más libremente que otros poetas con los villancicos "en metáfora de" y rehacer el mismo motivo muchas veces. Impresiona el cuidado, además, con que confeccionaba los suyos. En su juego a san Pedro de 1677 trata el motivo de la oreja de Malco en cuatro ocasiones, mientras que en su otro juego al mismo santo de autoría "probada" (1683) no lo toca ni una sola vez. Es evidente que tuvo mucho cuidado de no repetirse. Aunque podemos ver que hay muchos villanciqueros en la Nueva España (algunos bastante buenos), podemos decir, tranquilamente, que sor Juana descuella entre todos.

Lo anterior puede darnos alguna idea de cómo hacían los autores de villancicos en la Nueva España para evitar que los fieles se quedaran dormidos en plenos maitines, pues como dice sor Juana "ya en el postrer Nocturno / está la gente cansada" (311, vv. 31-32). Si de un motivo tan prosaico y mundano como es una oreja rebanada han sacado, como el mago del sombrero, un manojo de versos tan bien logrados, ¿qué no harán con el pasaje de las negaciones, de las lágrimas o del caminar sobre las aguas de san Pedro, ese santo tan venerado en tierras novohispanas?

Jorge GutiÉRREZ REYNA 


\section{REFERENCIAS}

Alatorre, Antonio, "Carta de Sor Juana al padre Núñez”, Nueva Revista de Filología Hispánica, 35, 2, 1987, 591-673.

CRUZ, sor Juana Inés de la, Obras completas, t. II: Villancicos y letras sacras, ed., pról. y notas de Alfonso Méndez Plancarte, México, Fondo de Cultura Económica, 1952 (Biblioteca Americana, 21).

Marchante, León, Obras poéticas póstumas, t. II, Madrid, Gabriel del Barrio, 1733.

Méndez Plancarte, Alfonso, Poetas Novohispanos. Segundo siglo (1621-1721). Parte primera, México, Universidad Nacional Autónoma de México, 1994 (Biblioteca del Estudiante Universitario, 43).

Soto Espinosa, Pedro de, Villancicos que se cantaron en la santa iglesia catedral en los maitines del gloriosísimo príncipe de la Iglesia el señor san Pedro, Puebla, Juan de Borja, 1688.

Tenorio, Martha Lilia, Los villancicos de Sor Juana, México, El Colegio de México, 1999.

Tenorio, Martha Lilia, "Sor Juana y León Marchante", Nueva Revista de Filología Hispánica, 50: 2, 2002, 543-561.

Tenorio, Martha Lilia, Poesía novohispana. Antología, t. 2, presentación de Antonio Alatorre, México, El Colegio de México-Fundación para las Letras Mexicanas, 2010. 